\title{
Four Fourier transform spectrometers and the Arctic polar vortex: instrument intercomparison and ACE-FTS validation at Eureka during the IPY springs of 2007 and 2008
}

\author{
R. L. Batchelor ${ }^{1}$, F. Kolonjari ${ }^{1}$, R. Lindenmaier ${ }^{1}$, R. L. Mittermeier ${ }^{2}$, W. Daffer ${ }^{3}$, H. Fast ${ }^{2}$, G. Manney ${ }^{3,4}$, K. Strong ${ }^{1}$, \\ and K. A. Walker ${ }^{1,5}$ \\ ${ }^{1}$ Department of Physics, University of Toronto, Toronto, Ontario, Canada \\ ${ }^{2}$ Environment Canada, Downsview, Ontario, Canada \\ ${ }^{3}$ Jet Propulsion Laboratory, California Institute of Technology, Pasadena, California, USA \\ ${ }^{4}$ New Mexico Institute of Mining and Technology, Socorro, New Mexico, USA \\ ${ }^{5}$ Department of Chemistry, University of Waterloo, Waterloo, Ontario, Canada
}

Received: 6 October 2009 - Published in Atmos. Meas. Tech. Discuss.: 6 November 2009

Revised: 6 January 2010 - Accepted: 7 January 2010 - Published: 22 January 2010

\begin{abstract}
The Canadian Arctic Atmospheric Chemistry Experiment Validation Campaigns have been carried out at Eureka, Nunavut $\left(80.05^{\circ} \mathrm{N}, 86.42^{\circ} \mathrm{W}\right)$ during the polar sunrise period since 2004. During the International Polar Year (IPY) springs of 2007 and 2008, three ground-based Fourier transform infrared (FTIR) spectrometers were operated simultaneously. This paper presents a comparison of trace gas measurements of stratospherically important species involved in ozone depletion, namely $\mathrm{O}_{3}, \mathrm{HCl}, \mathrm{ClONO}_{2}, \mathrm{HNO}_{3}$ and $\mathrm{HF}$, recorded with these three spectrometers. Total column densities of the gases measured with the new Canadian Network for the Detection of Atmospheric Change (CANDAC) Bruker 125HR are shown to agree to within 3.5\% with the existing Environment Canada Bomem DA8 measurements. After smoothing both of these sets of measurements to account for the lower spectral resolution of the University of Waterloo Portable Atmospheric Research Interferometric Spectrometer for the Infrared (PARIS-IR), the measurements were likewise shown to agree with PARIS-IR to within 7\%. Concurrent measurements of these gases were also made with the satellite-based Atmospheric Chemistry Experiment Fourier Transform Spectrometer (ACE-FTS) during overpasses of Eureka during these time periods. While one of the mandates of the ACE satellite mission is to study ozone depletion in the polar spring, previous validation exercises have identified the highly variable polar vortex conditions of the spring period to be a challenge for validation efforts. In this
\end{abstract}

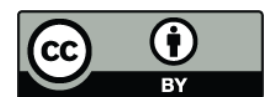

Correspondence to: R. L. Batchelor (rbatchelor@atmosp.physics.utoronto.ca) work, comparisons between the CANDAC Bruker 125HR and ACE-FTS have been used to develop strict criteria that allow the ground- and satellite-based instruments to be confidently compared. When these criteria are taken into consideration, the observed biases between the ACE-FTS and ground-based FTIR spectrometer are not persistent for both years and are generally insignificant, though small positive biases of $\sim 5 \%$, comparable in magnitude to those seen in previous validation exercises, are observed for $\mathrm{HCl}$ and $\mathrm{HF}$ in 2007, and negative biases of $-15.3 \%,-4.8 \%$ and $-1.5 \%$ are seen for $\mathrm{ClONO}_{2}, \mathrm{HNO}_{3}$ and $\mathrm{O}_{3}$ in 2008 .

\section{Introduction}

Ground-based instruments that measure the chemical composition of the atmosphere, through techniques such as solarabsorption spectroscopy, provide a key data set for the validation of satellite remote-sensing instruments (e.g., Dils et al., 2006; Vigouroux et al., 2007; Kerzenmacher et al., 2008; Dupuy et al., 2009). Biases and differences that are observed between ground-based and satellite instruments are, however, difficult to quantify due to the range of viewing geometries, and differences between individual instruments that are considered in a particular comparison. Side-by-side instrument intercomparisons, for example, have shown that total column densities of key stratospheric trace gases measured by ground-based Fourier transform infrared (FTIR) spectrometers may exhibit differences of several percent, even during times of stable atmospheric conditions and when retrieval algorithms are made as consistent as possible

Published by Copernicus Publications on behalf of the European Geosciences Union. 
(Goldman et al., 1999; Griffith et al., 2003; Meier et al., 2005; Wunch et al., 2007; Batchelor et al., 2009). Validation of the Atmospheric Chemistry Experiment - Fourier Transform Spectrometer (ACE-FTS) has likewise shown large differences between ground-based and satellite instruments, particularly during the highly-variable Arctic spring-time (e.g., Wolff et al., 2008; Mahieu et al., 2008). Comparisons made under these conditions thus require a comprehensive understanding of both the validating instrument and the viewing geometry with respect to polar vortex dynamics.

The Canadian Arctic ACE Validation Campaigns have been carried out during the polar sunrise period at the Polar Environment Atmospheric Research Laboratory (PEARL) at Eureka, Nunavut, Canada $\left(80.05^{\circ} \mathrm{N}, 86.42^{\circ} \mathrm{W}\right)$ since 2004 (Kerzenmacher et al., 2005; Fu et al., 2008; Fraser et al., 2008). The 2007 and 2008 campaigns extended from midFebruary until mid-April, and were additionally complemented by instrumentation installed at PEARL by the Canadian Network for the Detection of Atmospheric Change during 2006. One of these additions was a high-resolution Bruker 125HR Fourier transform spectrometer (Batchelor et al., 2009). This allowed simultaneous measurements of atmospheric composition to be made throughout the campaign by four Fourier transform spectrometers: three ground-based and one satellite-borne.

This paper provides an in-depth intercomparison between the three ground-based FTIR spectrometers co-located at PEARL during the International Polar Year Canadian Arctic ACE Validation Campaigns of 2007 and 2008, and validation of ACE-FTS data from the same period. Meteorological conditions were quite different between the two campaigns, with many measurements in 2007 being made inside the polar vortex where heterogeneous chemistry and ozone-depleting processes were occurring. A polar stratospheric warming prior to the start of the campaign in 2008, however, resulted in most of the measurements being made outside the vortex. As such, the two years provide a wide range of atmospheric conditions for the intercomparison. Key stratospheric trace-gas species $\mathrm{O}_{3}$, chlorine reservoirs $\mathrm{HCl}$ and $\mathrm{ClONO}_{2}$, fluorine reservoir $\mathrm{HF}$ and nitrogen reservoir $\mathrm{HNO}_{3}$ are investigated. Derived meteorological data along the instruments' line-ofsight are used to account for the changing conditions of the polar stratosphere, and a comprehensive set of measurement comparison criteria are identified for satellite validation near the polar vortex edge.

The paper is laid out as follows: Sect. 2 introduces the measurement site and the four FTIR spectrometers. Section 3 details the methodology used for the analyses, and is followed by the detailed intercomparison of the three ground-based instruments in Sect. 4. Section 5 then extends the ground-based intercomparison to include and validate measurements from the ACE-FTS using the Bruker $125 \mathrm{HR}$ Fourier transform spectrometer, before finishing with conclusions in Sect. 6.

\section{Measurement site and instrumentation}

The Polar Environment Atmospheric Research Laboratory, situated on Ellesmere Island, Nunavut, Canada $\left(80.05^{\circ} \mathrm{N}\right.$, $86.42^{\circ} \mathrm{W}, 610 \mathrm{~m}$ above sea level) is a modern, high-Arctic atmospheric research laboratory run by the Canadian Network for the Detection of Atmospheric Change (CANDAC). Atmospheric measurements made at PEARL sample the atmosphere from the ground to the top of the atmosphere. The PEARL site is situated $15 \mathrm{~km}$ from the Environment Canada Eureka Weather Station, and over $400 \mathrm{~km}$ from the nearest permanent settlement. At only $1100 \mathrm{~km}$ from the North Pole, it is a clean-air site in an ideal location for studying polar processes involved in ozone depletion. In addition, PEARL is ideally situated for the validation of polar-orbiting satellites, which typically sample nearby air several times a day.

The three ground-based FTIR spectrometers in operation at PEARL during the 2007 and 2008 validation campaigns were the Environment Canada ABB Bomem DA8 (henceforth the DA8) and the CANDAC Bruker IFS 125HR (henceforth the 125HR), which were both permanently housed in the PEARL FTS lab, and the campaign-only University of Waterloo Portable Atmospheric Research Interferometric Spectrometer for the Infrared (PARIS-IR). The three spectrometers were physically located within meters of each other, and shared a common solar beam from a custom-built solar tracker located on the roof of the laboratory. Approximately $1 / 3$ of the beam was directed to the PARIS-IR, and the other $2 / 3$ was alternately directed to the $125 \mathrm{HR}$ and the DA8. Details of each of the instruments are given below.

\subsection{Environment Canada ABB Bomem DA8}

The Environment Canada ABB Bomem DA8 FTIR spectrometer was installed at PEARL in 1993 and has provided atmospheric solar absorption spectra each spring over the past fifteen years (Donovan et al., 1997; Farahani et al., 2007; Paton-Walsh et al., 2008; Fu et al., 2008; Fast et al., 2010). The DA8 spectrometer is a vertically aligned Michelson interferometer equipped with two separate detectors: an InSb and a $\mathrm{HgCdTe}$ (commonly known as an MCT). Used with a $\mathrm{KBr}$ beamsplitter and a set of narrow band interference filters, the DA8 can record radiation over the spectral range from $700 \mathrm{~cm}^{-1}$ to $5000 \mathrm{~cm}^{-1}$ at a resolution of $0.004 \mathrm{~cm}^{-1}$ (where resolution is defined as $1 /$ maximum optical path difference $(\mathrm{MOPD})$ and $\mathrm{MOPD}=250 \mathrm{~cm})$. Eight interference filters are used in sequence in order to optimize the signalto-noise ratio (SNR). Measurements each consist of four coadded spectra, taking approximately twelve minutes, Fourier transformed with a Hamming apodization.

\subsection{CANDAC Bruker IFS 125HR}

The CANDAC Bruker IFS 125HR FTIR spectrometer is a high-resolution spectrometer that was installed at PEARL in August 2006 and operates throughout the sunlit parts of 
the year. It has been described in depth by Batchelor et al. (2009). Like the DA8, the 125HR measures on either an $\mathrm{InSb}$ or MCT detector with a $\mathrm{KBr}$ beamsplitter and uses a sequence of narrow band interference filters covering the $600-4300 \mathrm{~cm}^{-1}$ spectral range. Solar absorption measurements made during the IPY Arctic campaigns each consist of four co-added spectra recorded in both the forwards and backwards directions (taking approximately six minutes) at a resolution of $0.004 \mathrm{~cm}^{-1}(\mathrm{MOPD}=250 \mathrm{~cm})$. No apodization is applied to these measurements.

\subsection{University of Waterloo PARIS-IR}

The University of Waterloo Portable Atmospheric Research Interferometric Spectrometer for the Infrared is an ABB Bomem custom-built interferometer that is based on the design of the Fourier transform spectrometer onboard the Atmospheric Chemistry Experiment, and is built from its spare parts. A resolution of $0.02 \mathrm{~cm}^{-1}(\mathrm{MOPD}= \pm 25 \mathrm{~cm}$, with resolution defined to be consistent with the ACE-FTS, i.e., 0.5/MOPD) is achieved using corner cube reflectors mounted on a pivoting arm to introduce an optical path difference, as detailed in $\mathrm{Fu}$ et al. (2008). Interferograms are recorded on a sandwich $\mathrm{InSb} / \mathrm{MCT}$ detector with no filters, allowing the entire $750-4400 \mathrm{~cm}^{-1}$ spectral region to be measured simultaneously. Each IPY spring measurement consists of 20 co-added spectra, taking approximately six minutes, with no applied apodization.

\subsection{ACE-FTS}

In addition to the three ground-based instruments, the Atmospheric Chemistry Experiment (also known as SCISAT) also made measurements over Eureka during the campaigns. ACE was launched in August 2003, and orbits the Earth in a $74^{\circ}$ inclined circular orbit (Bernath et al., 2005). One of its primary aims is to observe the polar regions during active periods of ozone depletion chemistry, notably during the polar springtime. As such, it has multiple measurements over Eureka during this time period. The primary instrument onboard ACE is a Fourier transform spectrometer which simultaneously measures vertical profiles of more than 30 different atmospheric species, as well as temperature and pressure, using the solar occultation method (Bernath et al., 2005). The spectral range of the ACE-FTS is comparable to that of the ground-based FTIR spectrometers, with a spectral resolution of $0.02 \mathrm{~cm}^{-1}$, however, due to the limb-sounding geometry, the satellite-borne spectrometer has considerably more vertical resolution (typically $3-4 \mathrm{~km}$ ) than any of the groundbased instruments (Boone et al., 2005).

\section{Data analysis}

\subsection{Ground-based FTIR spectrometers}

Total column densities of $\mathrm{O}_{3}, \mathrm{HCl}, \mathrm{ClONO}_{2}, \mathrm{HNO}_{3}$ and $\mathrm{HF}$ covering the region between the ground and $100 \mathrm{~km}$ have been determined from the recorded spectra of each of the ground-based spectrometers in a consistent manner. Altitude-dependent atmospheric volume mixing ratio (VMR) profiles were retrieved from the spectra using SFIT2 (Pougatchev et al., 1995), a profile retrieval algorithm based on the optimal estimation technique of Rodgers (1976, 2000) whereby a calculated spectrum is fitted to the measured one by adjustment of the VMR profile. Total column densities were determined by integrating the retrieved trace gas and atmospheric density profiles throughout the column. The HITRAN 2004 + updates line list was used with SFIT2 v3.92c for the 125HR and PARIS-IR retrievals and v3.91 for the DA8 (the differences between the two versions being insignificant for this work). The retrieval parameters used have been described in Batchelor et al. (2009). The only difference from that work is that for PARIS-IR, retrievals have been performed on a 29- rather than the 38-layer grid used for the DA8 and $125 \mathrm{HR}$, to allow for its lower spectral resolution. This has been previously shown to result in differences in the retrieved column of less than $0.6 \%$ (Wunch et al., 2007), but helps to reduce unphysical oscillations in the retrieved profile. A priori VMR profiles and covariances, described in Sung et al. (2010), were consistent for all three instruments, while ad hoc SNR ratios, which are used for determining the measurement covariance, were selected for each gas for each instrument using the trade-off curve method described in Batchelor et al. (2009) to customize for the noise level in the spectra of the individual instruments. Daily pressure/temperature profiles, determined from the average of twice-daily radiosondes launched at Eureka, coupled to the National Centers for Environmental Prediction analyses above balloon height to $50 \mathrm{~km}$ and then to the US standard atmosphere to $100 \mathrm{~km}$, have been used for all three instruments. A summary of the spectral microwindows that have been fitted for each of the retrievals is presented in Table 1. The degrees of freedom of signal (DOFS), defined in this case as the trace of the averaging kernel, as well as an estimated error in the total column is also given. These have been calculated for each of the gases as described in Batchelor et al. (2009).

\subsection{ACE-FTS}

Trace gas volume mixing ratio and temperature/pressure profiles are retrieved from ACE-FTS spectra with a nonlinear least squares global fitting algorithm, as detailed in Boone et al. (2005). Profiles are retrieved from the cloud tops, or approximately $5 \mathrm{~km}$ in clear conditions, to approximately $100 \mathrm{~km}$. ACE-FTS v2.2 measurements (including updates for $\mathrm{O}_{3}, \mathrm{~N}_{2} \mathrm{O}_{5}$ and $\mathrm{HDO}$ ) have been extensively validated 
Table 1. Summary of retrieval microwindows and interfering species, with estimated total uncertainty and DOFS. Multiple microwindows are fitted simultaneously where more than one region is specified. Interfering trace gas species are scale fitted, unless profile fitting is indicated by a $(\mathrm{P})$. Total uncertainty has been calculated, with individual uncertainties resulting from measurement, smoothing and model parameter errors added in quadrature, as described in Batchelor et al. (2009). The DOFS are representative values for spectra recorded at the beginning of March, when solar zenith angles of are typically $>80^{\circ}$. Abbreviations used in the headers are $125=125 \mathrm{HR}$ and PIR=PARIS-IR .

\begin{tabular}{|c|c|c|c|c|c|c|c|c|}
\hline \multirow[t]{2}{*}{ Gas } & \multirow{2}{*}{$\begin{array}{l}\text { Microwindow }(\mathrm{s}) \\
\left(\mathrm{cm}^{-1}\right)\end{array}$} & \multirow[t]{2}{*}{ Interfering species } & \multicolumn{3}{|c|}{ Total Uncertainty (\%) } & \multicolumn{3}{|c|}{ DOFS } \\
\hline & & & 125 & DA8 & PIR & 125 & DA8 & PIR \\
\hline $\mathrm{O}_{3}$ & $1000.0-1004.5$ & $\begin{array}{l}\mathrm{H}_{2} \mathrm{O}, \mathrm{CO}_{2}, \mathrm{O}_{3} 676, \mathrm{O}_{3} 667 \\
\mathrm{O}_{3} 686, \mathrm{O}_{3} 668, \mathrm{C}_{2} \mathrm{H}_{4}\end{array}$ & 3.9 & 3.7 & 6.8 & $\sim 7.5$ & $\sim 7.5$ & $\sim 4.5$ \\
\hline $\mathrm{HCl}$ & $\begin{array}{l}2775.72-2775.8 \\
2821.4-2821.62 \\
2925.75-2926.05\end{array}$ & $\begin{array}{l}\mathrm{O}_{3}, \mathrm{CH}_{4}, \mathrm{~N}_{2} \mathrm{O} \\
\mathrm{HDO}, \mathrm{N}_{2} \mathrm{O} \\
\mathrm{CH}_{4}, \mathrm{NO}_{2}, \mathrm{OCS}, \mathrm{O}_{3}\end{array}$ & 3.4 & 3.1 & 11.8 & $\sim 3$ & $\sim 3$ & $\sim 1$ \\
\hline $\mathrm{ClONO}_{2}$ & $\begin{array}{l}779.85-780.45 \\
782.55-782.87 \\
938.3-939.3\end{array}$ & $\begin{array}{l}\mathrm{O}_{3}(\mathrm{P}), \mathrm{CO}_{2}(\mathrm{P}), \mathrm{HNO}_{3} \\
\mathrm{O}_{3}(\mathrm{P}), \mathrm{CO}_{2}(\mathrm{P}), \mathrm{H}_{2} \mathrm{O}, \mathrm{HNO}_{3} \\
\mathrm{CO}_{2}(\mathrm{P})\end{array}$ & 3.9 & 2.7 & N/A & $\sim 1$ & $\sim 1$ & N/A \\
\hline $\mathrm{HNO}_{3}$ & $867.5-870.0$ & $\mathrm{H}_{2} \mathrm{O}, \mathrm{OCS}, \mathrm{NH}_{3}$ & 8.1 & 10.1 & 10.3 & $\sim 3.5$ & $\sim 3.5$ & $\sim 1$ \\
\hline $\mathrm{HF}$ & $4038.78-4039.1$ & $\mathrm{H}_{2} \mathrm{O}, \mathrm{CH}_{4}, \mathrm{HDO}$ & 5.8 & 4.4 & 13.0 & $\sim 2.5$ & $\sim 2.5$ & $\sim 1$ \\
\hline
\end{tabular}

against other satellites and ground-based instruments, and show typical relative differences of $1-8 \%$ for $\mathrm{O}_{3}$ (Dupuy et al., 2009), 5-10\% for $\mathrm{HCl}$ (Mahieu et al., 2008), 1-14\% for $\mathrm{ClONO}_{2}$ (Wolff et al., 2008), 5-10\% for HF (Mahieu et al., 2008) and 2-28\% for $\mathrm{HNO}_{3}$ (Wolff et al., 2008) globally through the stratosphere. Satellite validation near the polar vortex edge is, however, a challenge (as shown, for example, in Wolff et al., 2008 and Mahieu et al., 2008) and as such, the validation of ACE during the highly variable Arctic sunrise period requires special consideration. This is the primary goal of the Canadian Arctic ACE Validation Campaigns. Previous comparisons between trace gas columns measured by the DA8, PARIS-IR and ACE-FTS from 2004-2006 have been presented in Fu et al. (2008) and Sung et al. (2010). As in previous validation activities, this work uses ACE-FTS v2.2 $+\mathrm{O}_{3}, \mathrm{HDO}$ and $\mathrm{N}_{2} \mathrm{O}_{5}$ updates.

\subsection{Derived meteorological products}

Solar absorption measurements sample the air mass between the sun and the instrument along the line-of-sight. During the spring period, the solar zenith angle is large, and as such, the air mass being sampled at a given altitude may be a considerable distance from the instrument itself. To account for this, especially when considering the polar vortex and changes in chemistry occurring around its edge, meteorological products are derived at locations along the line-of-sight using the GEOS Version 5.0.1 (GEOS-5) analyses (Reinecker et al., 2007). These products are Derived Meteorological Products (DMPs), and in this work, have been calculated for both the ground- and satellite- based measurements at series of altitudes in the stratosphere, namely at 14, 18, 20, 22, 24, 26,
30,36 and $46 \mathrm{~km}$, with ground-based line-of-sight calculations as described in Fu et al. (2008) and satellite-based calculations as described in Manney et al. (2007). The DMPs include temperature, pressure, winds, potential temperature and scaled potential vorticity. A full description of the data set used can be found in Manney et al. (2007). Scaled potential vorticity (sPV) from the DMPs has been used in this work to differentiate the extra- and inner-vortex air masses at each altitude. An sPV of $1.2 \times 10^{-4} \mathrm{~s}^{-1}$ has been used as a proxy for the outer edge of the polar vortex, while an sPV of $1.6 \times 10^{-4} \mathrm{~s}^{-1}$ has been used for the inner edge (e.g., Manney et al., 2008).

\section{Ground-based spectrometer intercomparison}

\subsection{Methodology}

The 2007 and 2008 campaigns were designed to provide the best instrument comparison conditions possible for the time of the year. As previously discussed, the three FTIR spectrometers shared a solar tracker, with the lower-resolution PARIS-IR measuring simultaneously with the alternately measuring $125 \mathrm{HR}$ and DA8 high-resolution instruments. Measurements with the high-resolution instruments were made successively with matching filters, in order to reduce the time between compared measurements, while PARIS-IR measured the full spectral range simultaneously.

During the polar spring period, the sun is very low and the air mass that is being sampled can vary considerably through the course of the day. As such, individual pairs of measurements from the ground-based instruments have been 
compared with stringent requirements for spatial and temporal agreement. PARIS-IR measurements were made simultaneously with those of the other two instruments, thus individual PARIS-IR measurements were compared with the corresponding DA8 and 125HR measurements that were less than six minutes apart in starting time. This represents the time taken for one PARIS-IR measurement. DA8 and 125HR measurements were recorded alternately, due to their larger solar beam requirements, and as such the time between compared measurements was necessarily larger. A limitation of $15 \mathrm{~min}$ between start times, allowing for the twelve minute interferogram recording time of the DA8 plus a couple of minutes to physically switch the beam between instruments, has been used.

While the 125HR and DA8 have near-identical spectral resolutions, and thus also see the atmosphere in a very similar way, PARIS-IR has a significantly lower spectral resolution. This results in a retrieved atmospheric profile that is less vertically resolved and more strongly influenced by the a priori profile than that retrieved by the higher-resolution instruments. The effect of this reduced resolution has been investigated in this work. Comparisons were first made without accounting for the difference in resolution in the retrieved profile, and were then repeated using total columns for the high-resolution instruments that were smoothed using the PARIS-IR averaging kernel, as described in Rodgers and Connor (2003). To do this, each profile retrieved by the higher-resolution instruments was interpolated to the PARISIR retrieval grid and smoothed using a representative PARISIR averaging kernel and a priori VMR profile, following Eq. (1) (reproduced from Rodgers and Connor, 2003, Eq. 4):

$\boldsymbol{x}_{s}=\boldsymbol{x}_{a}+\mathbf{A}\left(\boldsymbol{x}_{h}-\boldsymbol{x}_{a}\right)$

where $\boldsymbol{x}_{s}$ is the smoothed profile, $\boldsymbol{x}_{a}$ is the PARIS-IR a priori profile (which, in this case, was identical to that used by the other two instruments), $\mathbf{A}$ is the PARIS-IR averaging kernel and $\boldsymbol{x}_{h}$ is the high-resolution instrument's retrieved profile. Total columns were then determined from the smoothed profile, using air mass densities derived from the daily pressure and temperature profiles measured over Eureka (Batchelor et al., 2009).

\subsection{Results and discussion}

Total column measurements of $\mathrm{O}_{3}, \mathrm{HCl}, \mathrm{ClONO}_{2}, \mathrm{HNO}_{3}$ and HF, as retrieved without accounting for the smoothing in the lower-resolution PARIS-IR, are shown in Fig. 1 for the 2007 and 2008 campaigns. Note that the very weak $\mathrm{ClONO}_{2}$ absorption features mean that retrievals are not reliable for PARIS-IR, and thus have not been included. Also shown in Fig. 1 is the scaled potential vorticity through the midstratosphere (at 18, 22 and $26 \mathrm{~km}$ ), indicating the conditions of the measurements relative to the vortex edge. The very different dynamical conditions over Eureka during these two years are clear, with measurements in 2007 being made well inside the polar vortex from approximately days 67 to 83, and measurements during 2008 being made no further in than the edge of the vortex region throughout the campaign. Thus measurements made during 2007 are more likely to sample air that has been subject to ozone-depleting chemical processes than those made during 2008. Consistent between the two years, however, is the comparison between the three FTIR spectrometers. The DA8 and 125HR show excellent agreement, with mean discrepancies less than $3.5 \%$ and with the range of variation over each spring in all of the gases being well captured. The agreement with PARIS-IR is more variable. For $\mathrm{O}_{3}$ and $\mathrm{HCl}$, the comparison is very good (with mean differences of $\sim 2$ and $5 \%$ respectively), while there is an obvious bias in the $\mathrm{HNO}_{3}$ results. Through both years, PARIS-IR consistently underestimates the total column of this gas relative to the other instruments, with the bias being greater when the $\mathrm{HNO}_{3}$ column is large. In HF, there are high biases in the PARIS-IR data relative to the higher-resolution instruments at the highest solar zenith angles, early in the campaigns, but these disappear by about day 75 when the sun is slightly higher in the sky.

From the properties of the $\mathrm{HNO}_{3}$ bias, we suspected that the cause of the difference between the FTIR spectrometers was due to a higher contribution of the a priori to the lower-resolution instrument's retrievals. During this time of year, our climatological mean a priori column (derived from the SPARC 2000 climatology averaged over latitudes greater than $68^{\circ} \mathrm{N}$ during the sunlit parts of the year) is considerably lower than the real $\mathrm{HNO}_{3}$ columns, which have been building up throughout the polar night. If this was indeed a major cause of the discrepancy, then smoothing the profiles retrieved with the higher-resolution instruments by the PARISIR averaging kernel and a priori profile should result in a better comparison. Figure 2 illustrates the smoothing process. In the top panel, the unsmoothed $125 \mathrm{HR} \mathrm{HNO}_{3}$ total columns for 2008 are shown with the corresponding PARISIR columns. The a priori column is also plotted, showing clearly that the a priori is much lower than the columns retrieved from the measurements. The slight variation in the a priori column from day to day reflects the changing atmospheric density profile. The middle panel shows the $125 \mathrm{HR}$ $\mathrm{HNO}_{3}$ columns before (red) and after (cyan) they have been smoothed using Eq. (1). The smoothing effect inherent in the lower-resolution PARIS-IR retrievals is clear - the smoothed 125HR measurements are typically much closer to the a priori than the unsmoothed ones. The new comparison between PARIS-IR and the 125HR (smoothed) is shown in the bottom panel, and the improvement in the comparison is significant. A correlation plot highlighting the improvement in the correlation between the $\mathrm{HNO}_{3}$ columns after the smoothing is shown in Fig. 3.

It should be noted that under these conditions, we expect that the absolute values measured by the higher-resolution 125HR and DA8 instruments would be more representative of the true atmosphere than those measured by PARIS-IR, 


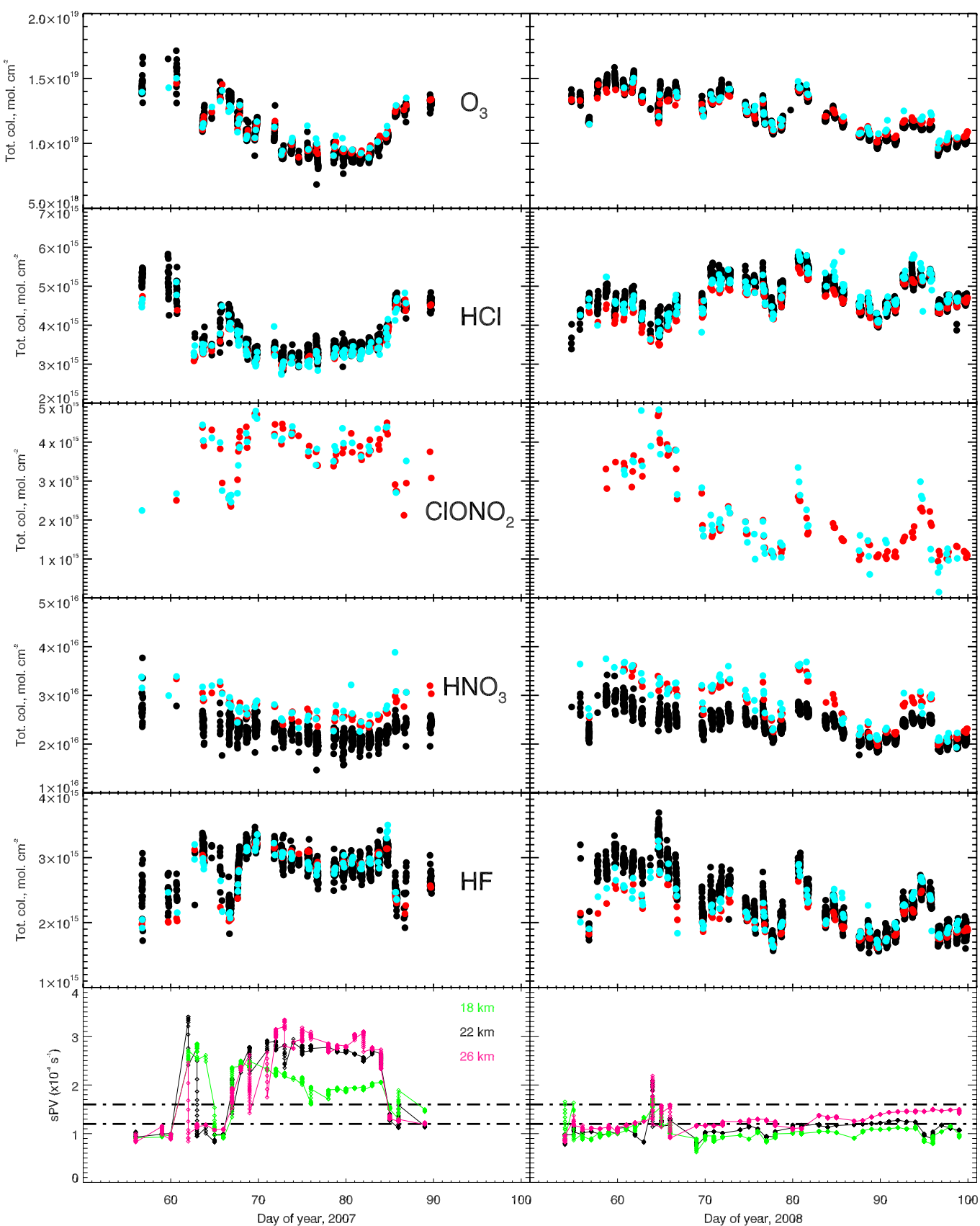

Fig. 1. Time series showing total column densities of (from top to bottom): $\mathrm{O}_{3}, \mathrm{HCl}, \mathrm{ClONO}_{2}, \mathrm{HNO}_{3}$ and $\mathrm{HF}$ for the 2007 (left panels) and 2008 (right panels) campaigns. 125HR measurements are shown in red, DA8 in cyan and PARIS-IR in black. The scaled potential vorticity (sPV) at 18,22 and $26 \mathrm{~km}$ is shown in the bottom panel for each year, with approximate locations of the vortex inner and outer edges marked by the dot-dashed lines. Error bars are omitted for clarity. See Table 1 for total uncertainties.

due to the lower information content in the PARIS-IR measurements. The smoothing effects of the instruments are, however, largely taken into consideration in the error budget, with higher quoted uncertainties for the PARIS-IR total columns (Table 1) reflecting the higher uncertainty relating to the greater smoothing in these measurements.
The smoothing process was applied to the retrieved $125 \mathrm{HR}$ and DA8 profiles in a similar manner for each of the other gases, and the revised time series (excluding $\mathrm{ClONO}_{2}$ ) are shown in Fig. 4. A summary of the comparisons, including mean difference, standard deviation and correlation for both the smoothed and unsmoothed total column comparisons and incorporating both 2007 and 2008 data to cover a wide range of conditions, is shown in Table 2. 


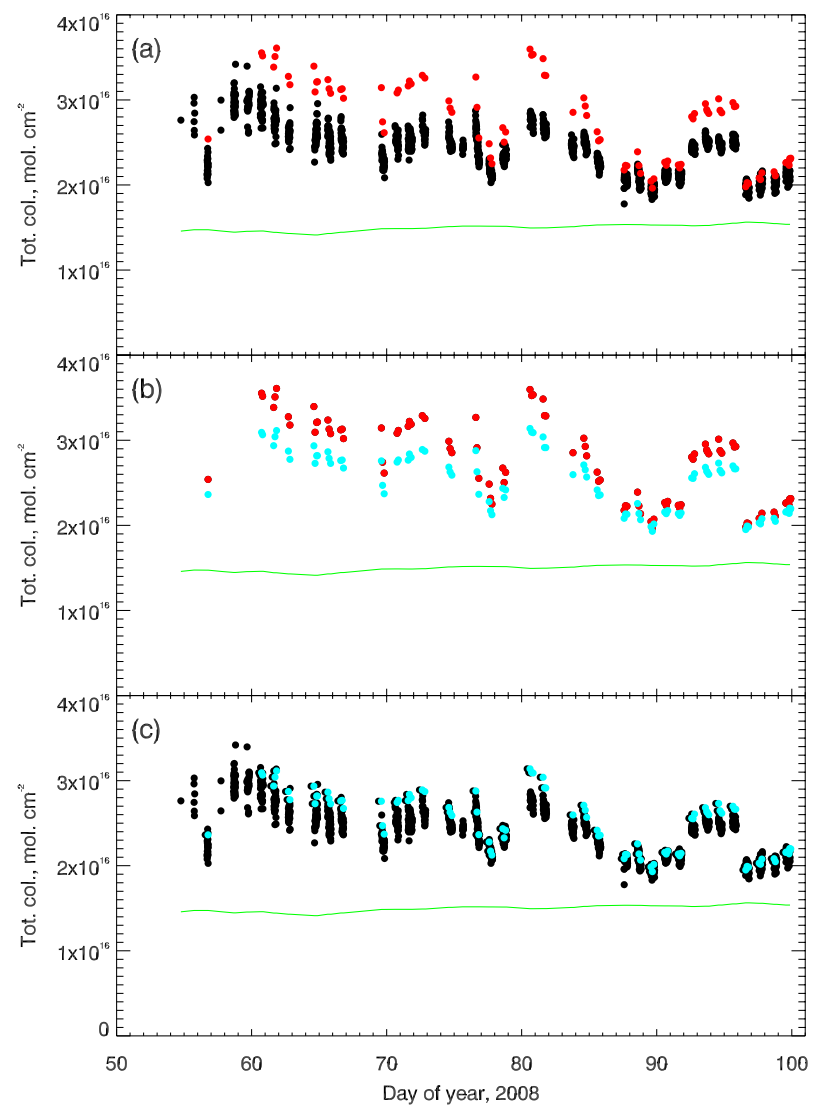

Fig. 2. Illustration of the smoothing process defined by Eq. (1). (a) shows the total $\mathrm{HNO}_{3}$ column measured by the $125 \mathrm{HR}$ in red, and by PARIS-IR in black. The a priori column is shown by the green line. (b) shows the same 125HR measurements in red, and the resulting $125 \mathrm{HR}$ measurements after smoothing via Eq. (1) in cyan. (c) shows the new comparison between the smoothed $125 \mathrm{HR}$ (cyan) and PARIS-IR (black).

For the two gases for which the biggest biases were seen in Fig. 1, notably $\mathrm{HNO}_{3}$ and $\mathrm{HF}$, the agreement between the three spectrometers is substantially improved by accounting for the differences in vertical resolution. Unfortunately the difference in $\mathrm{O}_{3}$ columns increases following smoothing with the PARIS-IR averaging kernels as the smoothing error had masked other sources of difference in the measurements. These measurement differences may include extra sensitivity of PARIS-IR retrievals to saturated features (caused by the extremely long path length at this time of year), detector linearity differences and real differences in the vertical distribution of the gas in parts of the atmosphere along the lineof-sight which are not well captured by the lower-resolution instrument (but are, as shown by the very high DOFS in Table 1 , well represented by the high-resolution instruments, resulting in substantial changes to the column after smoothing). Fortunately the difference in total columns between the instruments is still fairly small, and, as for all of the compared gases after smoothing, well within the error estimates of the individual measurements.
After accounting for the larger smoothing effect of the lower resolution PARIS-IR, the total column differences between the three spectrometers are less than $3.5 \%$ for the $125 \mathrm{HR}$ and DA8, and less than $6.5 \%$ for the comparisons between the $125 \mathrm{HR}$ or DA8 and the PARIS-IR. These differences are comparable in magnitude with other side-byside instrument comparisons carried out at Eureka (Fu et al., 2008; Paton-Walsh et al., 2009; Batchelor et al., 2009) and around the globe (Goldman et al., 1999; Griffiths et al., 2005; Wunch et al., 2007).

\section{Ground- and satellite-based spectrometer intercomparison}

\subsection{Methodology}

Having shown that measurements from the three groundbased spectrometers are comparable, validation of the satellite-based ACE-FTS has been carried out using just the new $125 \mathrm{HR}$, which has high spectral resolution, low uncertainties and more measurements than the DA8. Spectra were considered coincident if the 125HR and ACE-FTS measurements were recorded within 12 hours and the distance between the ACE 30-km tangent point and PEARL was less than $1000 \mathrm{~km}$.

Due to the difference in altitude sensitivity between the two instruments, partial, rather than total, column densities have been compared using ACE-FTS profiles smoothed to the resolution of the $125 \mathrm{HR}$, as described by Eq. (1). As in previous validation activities, for this comparison, each ACE-FTS profile was linearly interpolated from the $1 \mathrm{~km}$ spaced ACE grid to the 38-layer altitude grid used for the $125 \mathrm{HR}$ retrievals, and then smoothed with the $125 \mathrm{HR}$ averaging kernel and a priori profile corresponding to the matching $125 \mathrm{HR}$ spectrum. In the tropospheric region where no ACE-FTS data were available, the profile values were filled with the corresponding $125 \mathrm{HR}$ 's a priori profile for the calculation. Partial columns were then determined for each measurement pair for the altitude range for which ACE-FTS data existed for that measurement and where the sensitivity of the $125 \mathrm{HR}$ measurement, as determined from the sums of each row of the averaging kernel matrix, was at least 0.5 (Vigouroux et al., 2007; Wolff et al., 2008; Kerzenmacher et al., 2008).

Comparisons were made for $\mathrm{O}_{3}, \mathrm{HCl}, \mathrm{HF}, \mathrm{HNO}_{3}$, and $\mathrm{ClONO}_{2}$, with the mean and standard deviation of the differences between each pair of ACE-FTS and 125HR partial column values calculated. While the exact altitude range included in the partial column varied from pair to pair, these typically ranged from approximately $6-43 \mathrm{~km}\left(\mathrm{O}_{3}\right), 8$ $38 \mathrm{~km}(\mathrm{HCl}), 15-26 \mathrm{~km}\left(\mathrm{ClONO}_{2}\right), 8-29 \mathrm{~km}\left(\mathrm{HNO}_{3}\right)$ and $10-43 \mathrm{~km}(\mathrm{HF})$. Attempts to quantify the causes of differences in the partial columns determined from each spectrometer were investigated using the DMPs described in Sect. 3, and were used to further enhance the coincidence criteria. 


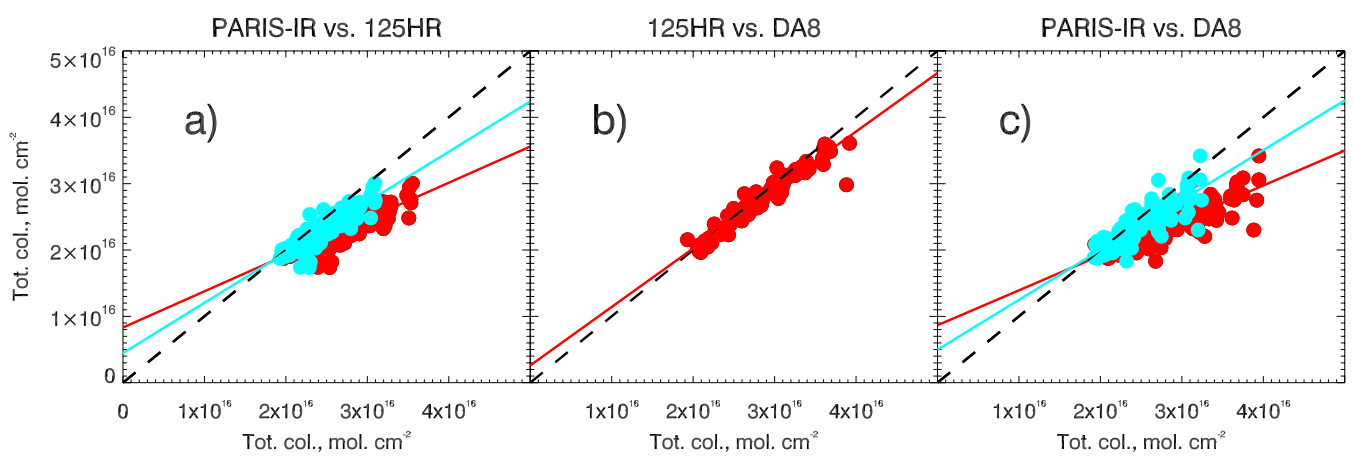

Fig. 3. Total column $\mathrm{HNO}_{3}$ plots demonstrating the correlation between each combination of the three instruments, before (red) and after (cyan) smoothing of the high-resolution measurements by the PARIS-IR averaging kernel. The 1-to-1 line is shown in black. (a) PARIS-IR (y-axis) vs 125HR (x-axis); (b) 125HR (y-axis) vs DA8 (x-axis); (c) PARIS-IR (y-axis) vs DA8 (x-axis). Note that no smoothing is necessary for the 125HR-DA8 comparison, as they are already at the same resolution. Slopes and correlation coefficients are given in Table 2.

Table 2. Comparisons between the three ground-based spectrometers, conducted using both unsmoothed, and smoothed $125 \mathrm{HR}$ and DA8 total columns from 2007 and 2008, as described in the text. Note that no smoothing is necessary for the 125HR-DA8 comparisons, as they have the same resolution. Difference $=($ inst $1-$ inst 2$) / 0.5($ inst $1+$ inst 2$)$, and Mean $=$ mean of these differences, calculated as a percentage. One standard deviation from the mean is also shown (Std Dev). The instrument names have been abbreviated: $125=125 \mathrm{HR}$, and PIR $=$ PARIS-IR. $R^{2}$ and Slope are derived from correlation plots, examples of which are shown in Fig. 3. $n$ indicates the number of matched pairs included in the statistics.

\begin{tabular}{|c|c|c|c|c|c|c|c|c|c|c|}
\hline \multirow[b]{2}{*}{ Gas } & \multirow[b]{2}{*}{ Instrument } & \multicolumn{4}{|c|}{ Unsmoothed } & \multicolumn{4}{|c|}{ Smoothed } & \multirow[b]{2}{*}{$n$} \\
\hline & & Mean (\%) & Std Dev (\%) & $R^{2}$ & Slope & Mean (\%) & Std Dev (\%) & $R^{2}$ & Slope & \\
\hline \multirow{3}{*}{$\mathrm{O}_{3}$} & 125-PIR & 1.15 & 3.75 & 0.98 & 1.18 & 6.46 & 3.76 & 0.98 & 1.12 & 266 \\
\hline & DA8-PIR & 2.14 & 4.72 & 0.96 & 1.10 & 5.44 & 5.35 & 0.94 & 1.01 & 142 \\
\hline & 125-DA8 & 1.50 & 2.16 & 0.99 & 0.95 & & & & & 92 \\
\hline \multirow{3}{*}{$\mathrm{HCl}$} & 125-PIR & -5.08 & 3.33 & 0.98 & 1.02 & 1.40 & 3.62 & 0.98 & 0.90 & 293 \\
\hline & DA8-PIR & -1.62 & 5.21 & 0.96 & 0.87 & 2.16 & 5.34 & 0.97 & 0.80 & 441 \\
\hline & $125-\mathrm{DA} 8$ & 3.50 & 4.74 & 0.97 & 0.83 & & & & & 174 \\
\hline $\mathrm{ClONO}_{2}$ & 125-DA8 & -1.35 & 23.84 & 0.97 & 0.92 & & & & & 89 \\
\hline \multirow{3}{*}{$\mathrm{HNO}_{3}$} & 125-PIR & 15.08 & 7.27 & 0.89 & 0.55 & 5.86 & 5.01 & 0.91 & 0.76 & 232 \\
\hline & DA8-PIR & 17.78 & 8.59 & 0.87 & 0.53 & 4.66 & 6.42 & 0.87 & 0.75 & 157 \\
\hline & $125-\mathrm{DA} 8$ & 2.52 & 4.14 & 0.97 & 0.88 & & & & & 102 \\
\hline \multirow{3}{*}{$\mathrm{HF}$} & 125-PIR & -4.48 & 7.96 & 0.93 & 0.93 & -2.85 & 7.80 & 0.95 & 1.31 & 230 \\
\hline & DA8-PIR & -1.86 & 7.73 & 0.91 & 0.97 & -1.34 & 8.48 & 0.89 & 1.09 & 285 \\
\hline & $125-\mathrm{DA} 8$ & 3.00 & 5.32 & 0.97 & 1.07 & & & & & 112 \\
\hline
\end{tabular}

\subsection{Results and discussion}

Figure 5 shows the partial columns, the percentage differences between the ACE-FTS and 125HR measurements (using (ACE-FTS - 125HR)/125HR), the distance between the two measurements, and the sPV for each of the gases for 2007 (top) and 2008 (bottom) respectively. The sPV along the line-of-sight has been determined for both the ACE-FTS and the 125HR as described in Sect. 3. From the number density profiles of each gas, it was determined that peak values were typically at approximately $18 \mathrm{~km}$, thus $\mathrm{SPV}$ values from that altitude were used as a proxy for the dynamical conditions being experienced for each measurement.
From the plot, we can see that while sometimes the partial columns measured by the two spectrometers are similar, at other times there are considerable differences. Occasionally these differences can be explained by either the physical distance between the measurements or by the fact that one measurement is recorded inside the polar vortex while the other is recorded outside (for example the $\mathrm{HCl}$ measurements on day 64,2007$)$. At other times, however, this does not fully explain the differences (for example on day 70, 2007 for the HF measurements). The differences observed between the ACE-FTS and 125HR using these simple time and location criteria, i.e., $12 \mathrm{~h}$ and $1000 \mathrm{~km}$ (from $30-\mathrm{km}$ tangent point to PEARL) are shown in Table 3. 


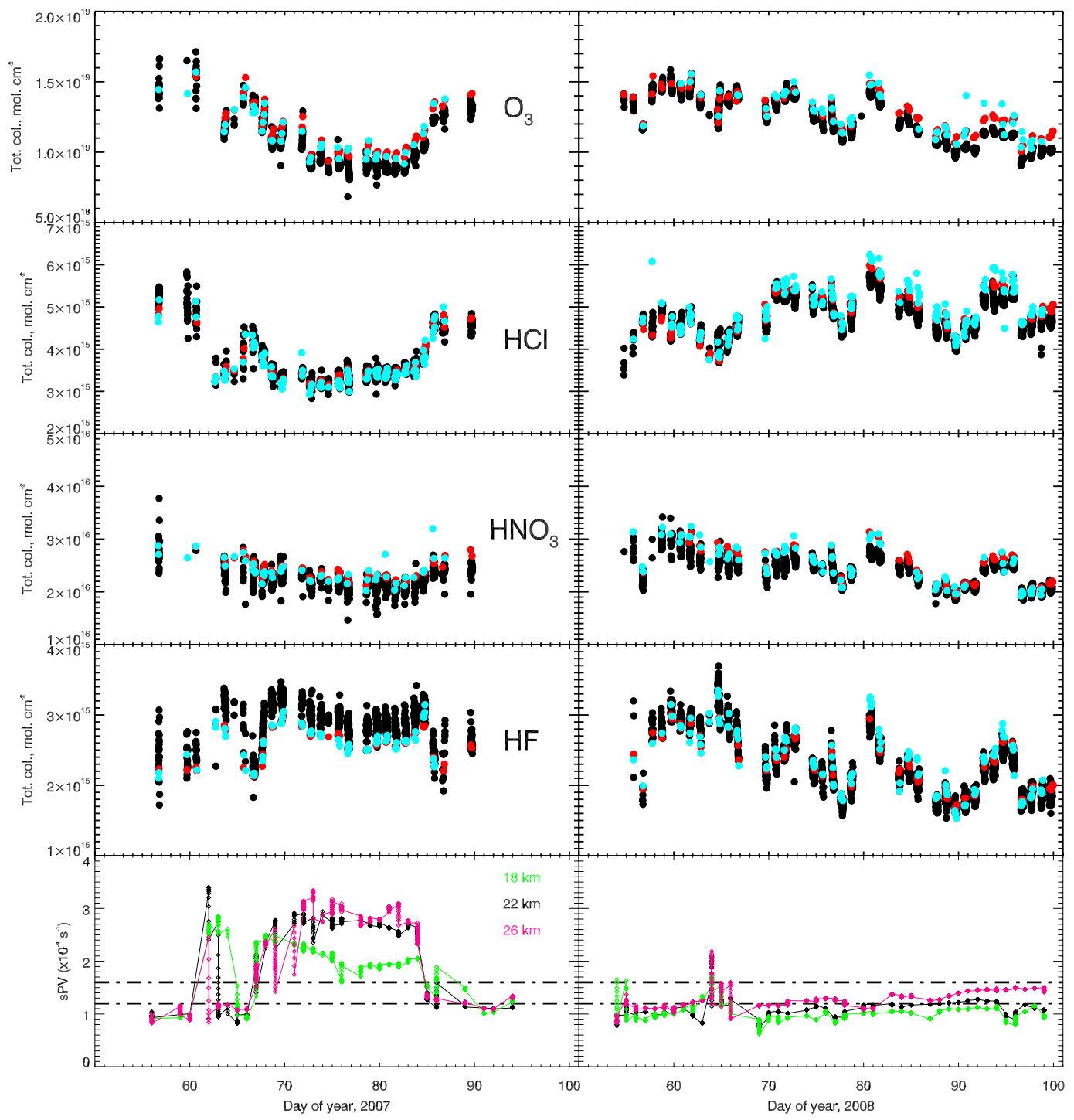

Fig. 4. Same as Fig. 1, with $125 \mathrm{HR}$ and DA8 smoothed to match the PARIS-IR resolution. Comparison statistics are given in Table 2.

Table 3. Mean percentage differences between ACE-FTS and 125HR partial columns (calculated as described in the text), one standard deviation from the mean (also as a percentage), standard error on the mean (standard deviation $/ \sqrt{ } n$ ), and the number of pairs of measurements (n) used in these calculations, for both 2007 and 2008. Note that the partial column altitude ranges varied for each individual comparison, but were typically around 6-43 km (O $\left.\mathrm{O}_{3}\right), 8-38 \mathrm{~km}(\mathrm{HCl}), 15-26 \mathrm{~km}\left(\mathrm{ClONO}_{2}\right), 8-29 \mathrm{~km}\left(\mathrm{HNO}_{3}\right)$ and $10-43 \mathrm{~km}(\mathrm{HF})$.

\begin{tabular}{|c|c|c|c|c|c|c|c|c|}
\hline & \multicolumn{4}{|c|}{2007} & \multicolumn{4}{|c|}{2008} \\
\hline & $\begin{array}{r}\text { Mean } \\
(\%)\end{array}$ & $\begin{array}{r}\text { Standard } \\
\text { deviation }(\%)\end{array}$ & $\begin{array}{l}\text { Standard } \\
\text { error }(\%)\end{array}$ & $n$ & $\begin{array}{r}\text { Mean } \\
(\%)\end{array}$ & $\begin{array}{r}\text { Standard } \\
\text { deviation }(\%)\end{array}$ & $\begin{array}{l}\text { Standard } \\
\text { error }(\%)\end{array}$ & $n$ \\
\hline $\mathrm{O}_{3}$ & -7.45 & 10.60 & 1.56 & 46 & -4.26 & 6.30 & 0.81 & 60 \\
\hline $\mathrm{HCl}$ & 0.28 & 9.76 & 1.30 & 56 & -1.93 & 7.67 & 0.94 & 67 \\
\hline $\mathrm{ClONO}_{2}$ & -4.94 & 15.98 & 2.41 & 44 & -17.60 & 16.92 & 2.22 & 58 \\
\hline $\mathrm{HNO}_{3}$ & -1.55 & 8.66 & 1.32 & 43 & -4.90 & 7.85 & 1.05 & 56 \\
\hline $\mathrm{HF}$ & 10.57 & 15.11 & 1.98 & 58 & 3.41 & 14.37 & 2.24 & 41 \\
\hline
\end{tabular}



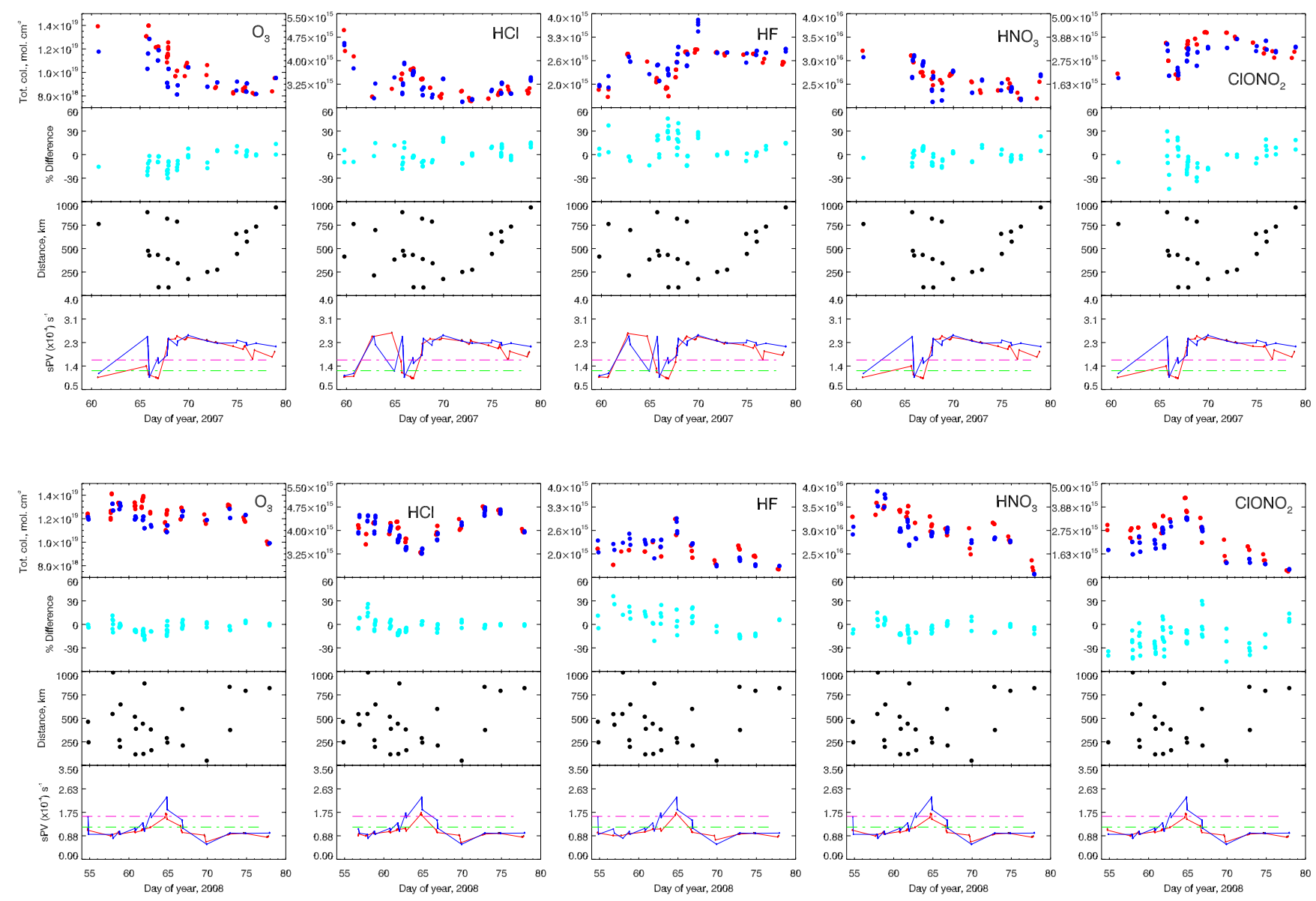

Fig. 5. Time series from 2007 (top plots) and 2008 (bottom plots) for (from left to right) $\mathrm{O}_{3}, \mathrm{HCl}, \mathrm{HF} \mathrm{HNO}_{3}$ and $\mathrm{ClONO}_{2}$. For each sub-plot, from top to bottom: Partial columns determined for ACE-FTS (blue) and 125HR (red); the percentage difference between the ACE-FTS and 125HR partial columns ((ACE-FTS - 125HR)/125HR); the distance between the two measurements as measured from the ACE $30-\mathrm{km}$ tangent point to PEARL; and the sPV for both ACE-FTS (red) and $125 \mathrm{HR}$ (blue) at $18 \mathrm{~km}$. The vortex edge region is marked by green dashed (outer) and magenta dashed (inner) lines.

From Table 3, some significant differences in the mean and especially in the standard deviation can be seen between the two years, with the more dynamically variable 2007 in most cases showing greater scatter in the differences (as seen by both the standard deviation and standard error) than in the more dynamically quiet 2008 . We believe this reflects the number of measurements that capture spectra measured in different locations relative to the location of the polar vortex. In almost no cases ( $\mathrm{HCl}$ in 2007 being the exception) are these measurements in agreement within the standard error. While the mean differences determined by this comparison are comparable to those determined in previous ACE-FTS validation exercises, we took the investigation a step further to better single out measurement pairs that should be comparable due to well-matched atmospheric conditions, thus improving our confidence in the quality of the comparison.

Looking first at the distance-between-measurements criterion, we determined that the $1000-\mathrm{km}$ criterion, as measured from the ACE $30-\mathrm{km}$ tangent point to the station, was not a particularly accurate representation of the distance between the actual air masses being sampled. Based on the derived meteorological product determinations of the longitude and latitude along the lines-of-sight of the measurement, we found that some measurements meeting the 1000$\mathrm{km}$ criterion were actually sampling air masses that were more than $1000 \mathrm{~km}$ apart, while other measurements which sampled air masses that were closer than $1000 \mathrm{~km}$ together were being excluded. An example of this is shown in Fig. 6, which shows two sets of differences for the $2007 \mathrm{O}_{3}$ comparison. The distance between the ACE 30-km tangent point and PEARL is shown in black and the distance between the $18-\mathrm{km}$ altitudes along the lines-of-sights of both the ACE and $125 \mathrm{HR}$ measurements is shown in orange. In order to ensure that all measurements that were within $1000 \mathrm{~km}$ of each other throughout the partial column were included, our ACE-FTS measurement sample was expanded to include all measurements within $2000 \mathrm{~km}$ of PEARL (based on the $30-\mathrm{km}$ tangent point altitude), in order to subsequently filter them to 


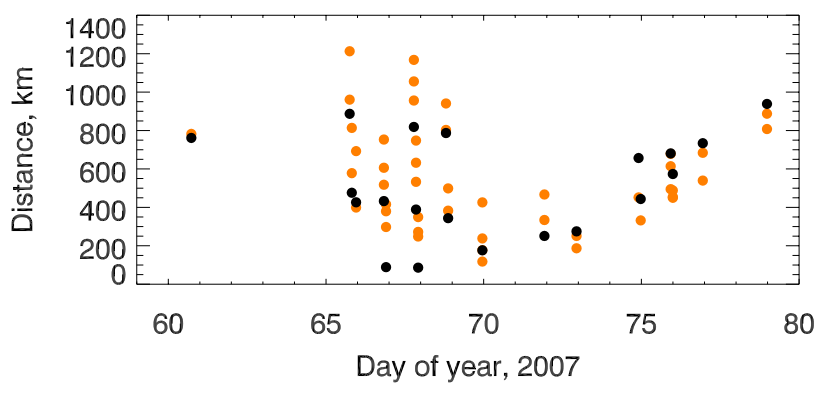

Fig. 6. Distance between comparable ACE-FTS and 125HR measurements, as measured from the ACE $30-\mathrm{km}$ tangent point to PEARL (black) and from the measurement location at $18 \mathrm{~km}$ for both instruments (orange).

$1000 \mathrm{~km}$ based on the distance between measurement points within the partial column. We also investigated the time criterion, but found little difference in the combinations that would be used for the comparison if the time criterion was set for 6,12 or $18 \mathrm{~h}$. This was a result of the limitation of sunlight for the ground-based instruments and the sunrise/sunset viewing geometry of the ACE-FTS.

To further refine the comparisons, for each pair, a plot of the SPV at each of the eight DMP altitudes along the line-ofsight for each instrument was constructed, with only those altitudes within the corresponding partial column altitude range being considered. Additional plots showing the temperature at each DMP location, the retrieved volume mixing ratio, and the distance between the measurement points were constructed. Examples of two of these plots, one showing a good match, and one showing a poor match, are shown in Figs. 7 and 8 respectively.

From these plots, we were able to determine whether the measurement conditions being sampled by the two instruments were similar throughout the height range of each comparison. The sPV and temperature profiles provided key information on the air mass with respect to the polar vortex and likely chemical processing conditions within, while the distance plot provided a measure of the physical separation of the sampled air masses. The retrieved VMR profiles provided additional information on where in the partial column the measurements were diverging. Note that the profiles shown for the ACE-FTS are the smoothed profiles, thus the smoothing effect of the $125 \mathrm{HR}$ has been taken into consideration. From the plots, it was clear that the sPV along the lines-of-sight was an important comparison criterion, as cases when both measurements were inside or both were outside, or even both measured through the vortex edge typically showed good agreement in the partial columns, while pairs for which the sPV was divergent typically had poorer agreement, as would be expected from the different air masses sampled. Temperature served as an additional important criterion, as within the polar vortex, chemical processing is highly dependent on temperature. As such, significant differences in temperature along the lines-of-sight for the two profiles, even when the sPV is similar, can indicate large differences in the sampled air masses.

Using the information gained by the plots, more rigorous coincidence criteria were developed to better identify comparable measurement pairs. While the temporal criterion of $12 \mathrm{~h}$ remained, the spatial coincidence criterion was tightened, requiring the distance between the measurement points at each of the DMP altitudes (rather than solely for the ACE 30-km tangent point to PEARL) to be within $1000 \mathrm{~km}$. Differences in SPV between the two measurements at each altitude along the line-of-sight were restricted to less than $0.3 \times 10^{-4} \mathrm{~s}^{-1}$, ensuring that the air masses relative to the polar vortex edge were similar for both measurements. Finally, the maximum temperature difference at each altitude point was set to $10 \mathrm{~K}$. The values of these criteria were selected to limit the likelihood of the measurements sampling different air masses, while ensuring that there were sufficient pairs of measurements remaining for a meaningful comparison.

Figure 9 shows the comparison between those measurements remaining after the new criteria were applied, with the mean percentage differences, standard deviations, and standard errors shown in Table 4. It can be seen that these stringent comparison requirements have significantly reduced the number of pairs contributing to the comparisons, particularly in 2007 when measurements made at Eureka were frequently near the edge of the polar vortex. However, both the mean differences and standard deviations between the two measurements have typically been reduced, and we are confident that these measurement pairs are highly comparable. The bias is seen to be zero within the standard error for $\mathrm{O}_{3}, \mathrm{ClONO}_{2}$ and $\mathrm{HNO}_{3}$ in 2007, with $\mathrm{ACE}$ showing a slight high bias of approximately $5 \%$ in $\mathrm{HCl}$ and $\mathrm{HF}$, which is comparable with that seen in previous ACE comparisons (Mahieu et al., 2008). In 2008, the $\mathrm{HCl}$ and $\mathrm{HF}$ biases are non-significant (within standard error), however negative biases are seen in the other gases. The greater standard deviation in $\mathrm{ClONO}_{2}$ reflects the difficulty of this retrieval, particularly when the column of $\mathrm{ClONO}_{2}$ is low (common outside the polar vortex, thus dominant in the 2008 comparison). This was previously demonstrated in Wolff et al. (2008), who described large standard deviations and found a wide range of biases between ACE-FTS and ground-based FTIR measurements around the globe, with no discernible trend. A slight negative bias in $\mathrm{ACE} \mathrm{HNO}_{3}$ was also reported in that study (Wolff et al, 2008), comparable in magnitude to that obtained here.

To conclude, having applied the stringent coincidence criteria, the differences between the two instruments are generally small and are in good agreement with previous ground-based FTIR/ACE-FTS comparisons of these five gases (Dupuy et al., 2009; Mahieu et al., 2008; Wolff et al., 2008). No clear bias is seen from year-to-year, and, in all cases, the difference between the measurements is zero to within one standard deviation, and non-significant in at least 


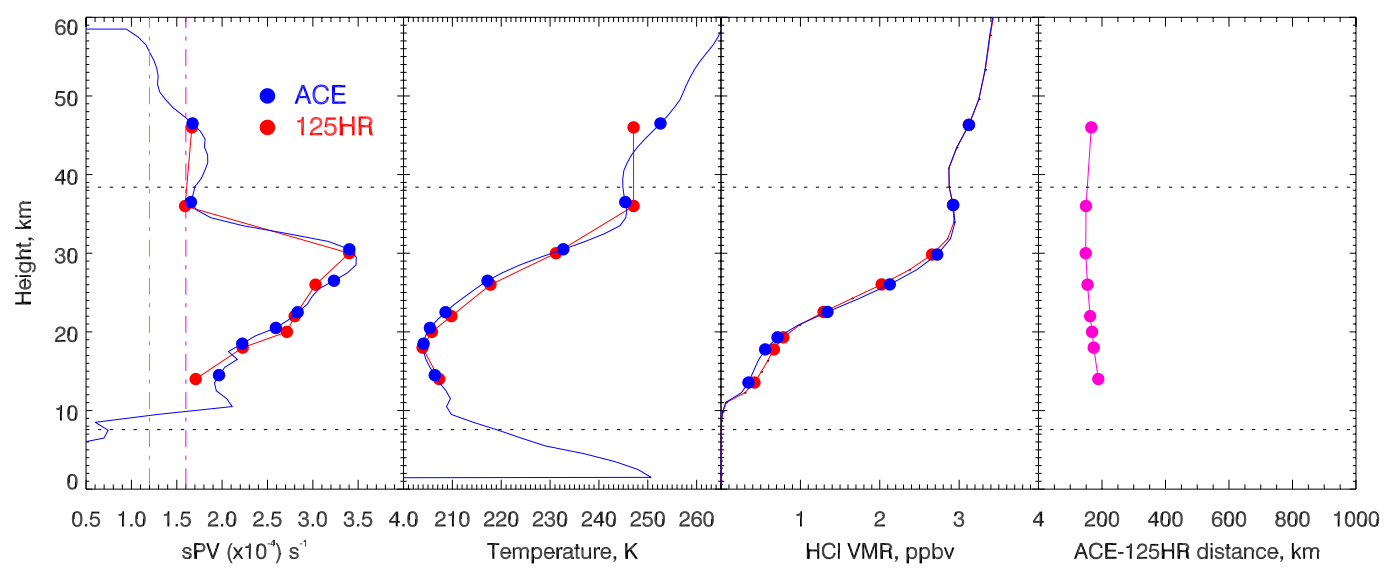

Fig. 7. Sample plots for determining the comparability of ACE-FTS and 125HR measurements. Plots from left to right show (a) the sPV (with inner and outer edge of the vortex marked with magenta and green dashed lines respectively), (b) temperature, (c) HCl VMR profile (where the ACE-FTS profile has been smoothed to match the 125HR), and (d) distance between ACE-FTS and 125HR measurements, with data being determined from DMPs along the lines-of-sight of each instrument. Dotted lines indicate the altitude range for the partial column used in this comparison. ACE-FTS information is shown in blue, and 125HR is shown in red. This example shows a well-matched comparison between $\mathrm{HCl}$ measurements made on the 13 March 2007 . The difference in the $9.82-38.40 \mathrm{~km}$ partial columns is $1.4 \%$.

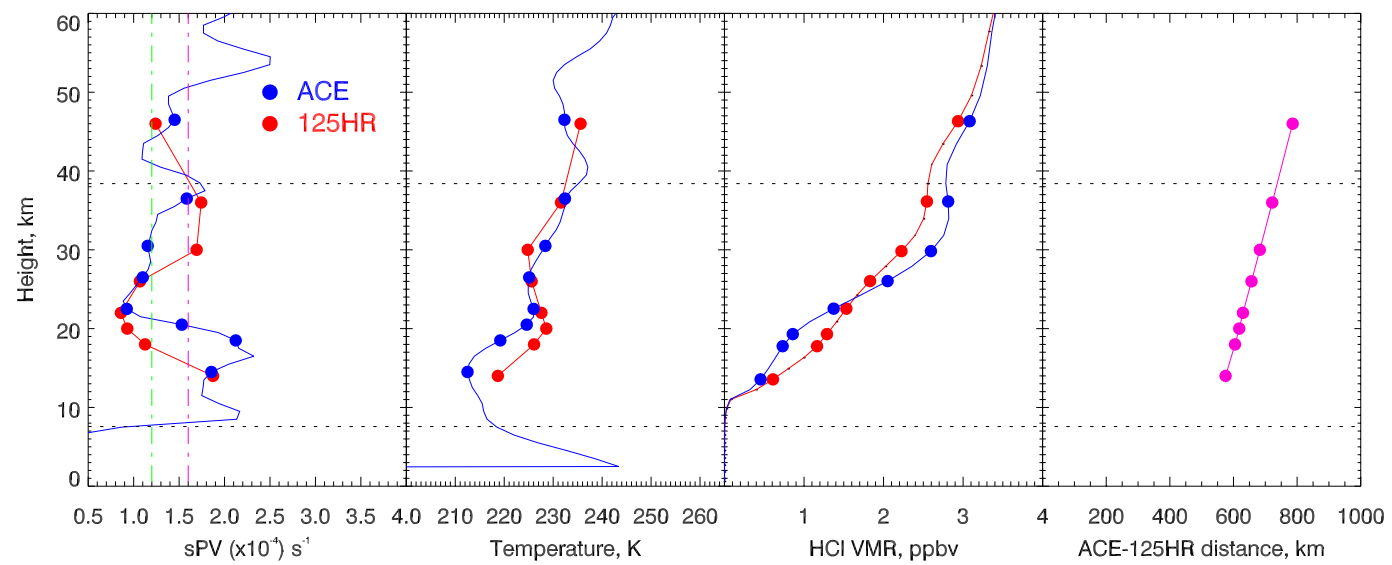

Fig. 8. As for Fig. 6, but demonstrating a less-well-matched comparison pair recorded on the 6 March 2007. Note the differences in sPV at 30 and $18 \mathrm{~km}$, with the two instruments each sampling a combination of air masses located inside and outside the polar vortex. The difference between the two measurements over the $11.02-38.40 \mathrm{~km}$ partial column is $10.0 \%$.

one of the years within standard error. As such, we can confidently say that the ACE-FTS shows excellent agreement with ground-based spectroscopic measurements made in the highly-variable spring-time northern polar stratosphere.

\section{Conclusions}

The 2007 and 2008 Canadian Arctic ACE Validation Campaigns at Eureka, Nunavut, have provided an excellent opportunity to compare measurements by four Fourier transform infrared spectrometers during the highly-variable Arctic polar sunrise period. Comparisons between the three ground-based FTIR spectrometers have shown small inter-instrumental differences well within the estimated uncertainties of the measurements and consistent with side-by-side intercomparisons conducted around the world. Total column trace gas measurements of $\mathrm{O}_{3}, \mathrm{HCl}, \mathrm{ClONO}_{2}$, $\mathrm{HF}$ and $\mathrm{HNO}_{3}$ made with the higher-resolution CANDAC Bruker 125HR were shown to compare with the comparable resolution Environment Canada ABB Bomem DA8 to within $3.5 \%$. Measurements of $\mathrm{O}_{3}, \mathrm{HCl}, \mathrm{HF}$ and $\mathrm{HNO}_{3}$ from both of these instruments were shown to agree to within $6.5 \%$ with the lower-resolution University of Waterloo PARISIR when the higher-resolution instruments' retrieved profiles were smoothed with the a priori profiles and averaging kernels of PARIS-IR to account for the larger smoothing effect of that instrument. The importance of this smoothing was demonstrated, particularly for cases when the atmospheric total column is considerably different from the a priori value. 

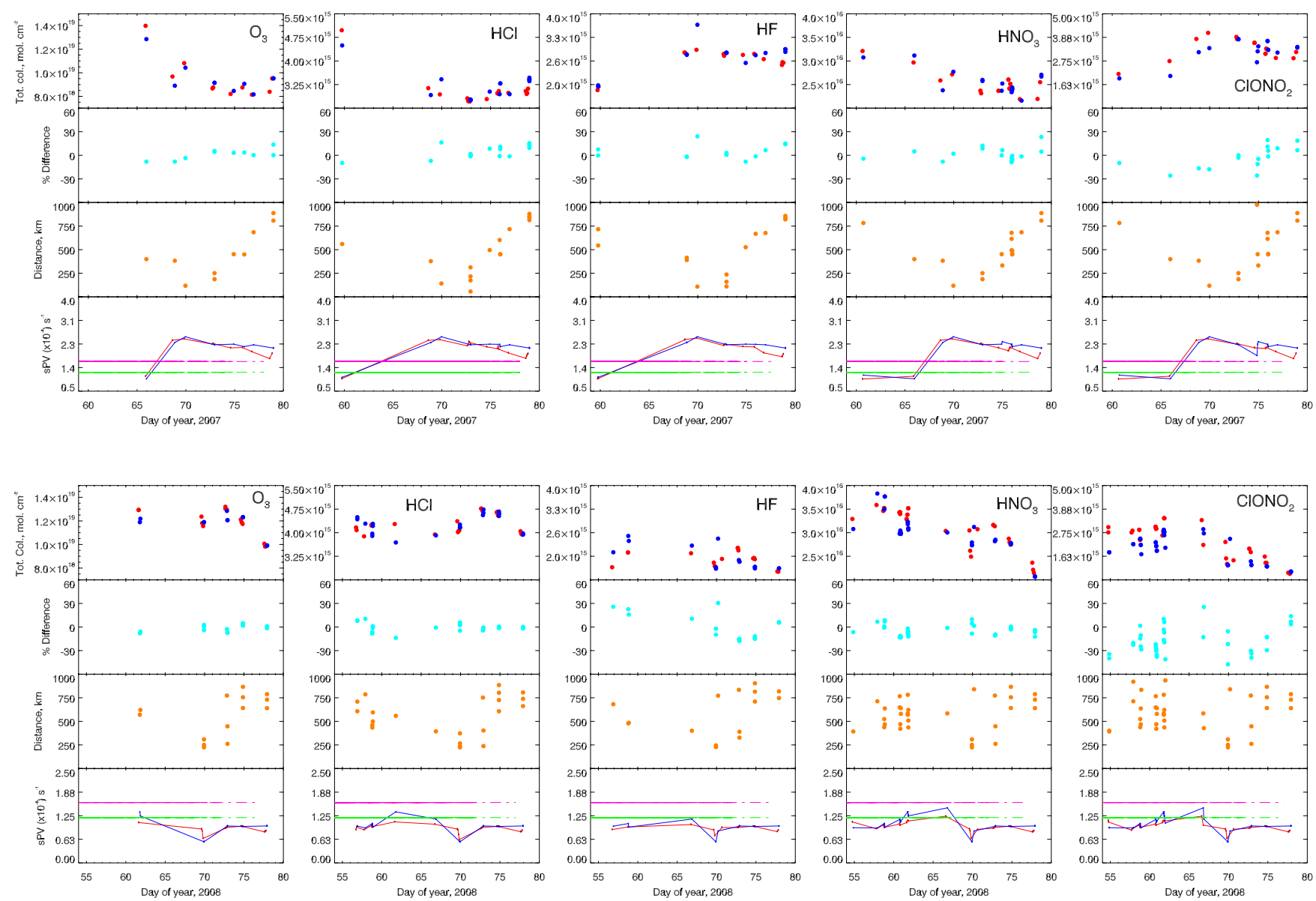

Fig. 9. As for Fig. 5, but with those comparison pairs remaining after tightened criteria have been applied. Note that the distances shown in this plot are now the distance between the measurements along the lines-of-sight at $18 \mathrm{~km}$, as described in the text.

Table 4. As for Table 3, but for pairs remaining after applying rigorous co-location criteria.

\begin{tabular}{|c|c|c|c|c|c|c|c|c|}
\hline & \multicolumn{4}{|c|}{2007} & \multicolumn{4}{|c|}{2008} \\
\hline & $\begin{array}{r}\text { Mean } \\
(\%)\end{array}$ & $\begin{array}{r}\text { Standard } \\
\text { deviation }(\%)\end{array}$ & $\begin{array}{l}\text { Standard } \\
\text { error }(\%)\end{array}$ & $n$ & $\begin{array}{r}\text { Mean } \\
(\%)\end{array}$ & $\begin{array}{r}\text { Standard } \\
\text { deviation }(\%)\end{array}$ & $\begin{array}{l}\text { Standard } \\
\text { error }(\%)\end{array}$ & $n$ \\
\hline $\mathrm{O}_{3}$ & 1.11 & 6.57 & 2.08 & 10 & -1.51 & 4.30 & 1.15 & 14 \\
\hline $\mathrm{HCl}$ & 4.86 & 8.05 & 2.01 & 16 & -0.23 & 5.38 & 1.12 & 23 \\
\hline $\mathrm{ClONO}_{2}$ & -2.86 & 14.24 & 3.56 & 16 & -15.33 & 22.62 & 3.72 & 37 \\
\hline $\mathrm{HNO}_{3}$ & 1.09 & 8.36 & 2.03 & 17 & -4.77 & 6.97 & 1.23 & 32 \\
\hline $\mathrm{HF}$ & 5.23 & 8.88 & 2.37 & 14 & 1.14 & 16.81 & 14.34 & 15 \\
\hline
\end{tabular}

Validation of the ACE-FTS v2.2 (with $\mathrm{O}_{3}, \mathrm{~N}_{2} \mathrm{O}_{5}$ and $\mathrm{HDO}$ updates) results from this time was also carried out with the 125HR. Strict coincidence criteria for use around the polar vortex were determined, utilizing DMP data along the linesof-sight of both instruments. These criteria were: measurement times less than $12 \mathrm{~h}$; distance between measurement points at multiple altitudes within the partial column less than $1000 \mathrm{~km}$; differences in sPV between measurements at multiple altitudes within the partial column less than $0.3 \times 10^{-4} \mathrm{~s}^{-1}$; and temperature differences at each altitude less than $10 \mathrm{~K}$. After applying these criteria, the mean biases between the ACE-FTS and 125HR for 2007/2008 were $1.1 /-1.5 \%, 4.9 /-0.2 \%,-2.9 /-15.3 \%, 1.1 /-4.8 \%$ and $5.2 / 1.1 \%$ for $\mathrm{O}_{3}, \mathrm{HCl}, \mathrm{ClONO}_{2}, \mathrm{HNO}_{3}$, and $\mathrm{HF}$ respectively. These values were generally insignificant within the standard error, though show slight high biases in $\mathrm{HCl}$ and $\mathrm{HF}$ in 2007, 
and low biases in $\mathrm{HNO}_{3}, \mathrm{ClONO}_{2}$ and $\mathrm{O}_{3}$ in 2008. Thus it can be concluded that satellite validation can be conducted with ground-based measurements made around the polar vortex edge, provided that comparison criteria are enhanced to account for vortex conditions along the line-of-sight, and that no annually-consistent bias can be identified in the ACE-FTS partial columns at this time of year.

Acknowledgements. This work would not have been possible without the support of the Canadian Space Agency (CSA), the Environment Canada (EC) Eureka Weather Station, and the Canadian Network for the Detection of Atmospheric Change (CANDAC). We particularly acknowledge the assistance of the CANDAC Operations Team, James Drummond (Principal Investigator), Pierre Fogal (PEARL Facilities Manager), Ashley Harrett, Alexei Khmel, Paul Loewen, Oleg Mikhailov and Matt Okraszewski for their assistance in collecting the measurements and transporting us between the lab and the station, and the EC meteorological technicians for launching many radioand ozone-sonde balloons for us. The Canadian Arctic ACE Validation Campaigns are supported by the CSA, EC, Natural Sciences and Engineering Research Council (NSERC) and the Northern Scientific Training Program. CANDAC and PEARL are funded by the Atlantic Innovation Fund/Nova Scotia Research Innovation Trust, Canadian Foundation for Climate and Atmospheric Sciences (CFCAS), Canadian Foundation for Innovation, CSA, EC, Government of Canada IPY funding, NSERC, Ontario Innovation Trust, Ontario Research Fund and the Polar Continental Shelf Program. Work carried out at the Jet Propulsion Laboratory, California Institute of Technology was done under contract with the National Aeronautics and Space Administration. The Atmospheric Chemistry Experiment, also known as SCISAT, is a Canadian-led mission mainly supported by the CSA and NSERC.

Edited by: H. Worden

\section{References}

Batchelor, R. L., Strong, K., Lindenmaier, R. L., Mittermeier, R., Fast, H., Drummond, J. R., and Fogal, P. F.: A new Bruker IFS 125HR FTIR spectrometer for the Polar Environment Atmospheric Research Laboratory at Eureka, Canada measurements and comparison with the existing Bomem DA8 spectrometer, J. Atmos. Oceanic Technol., 26, 1328-1340, doi:10.1175/2009JTECHA1215.1, 2009.

Bernath, P. F., McElroy, C. T., Abrams, M. C., Boone, C. D., Butler, M., Camy-Peyret, C., Carleer, M., Clerbaux, C., Coheur, P.-F., Colin, R., DeCola, P., DeMaziere, M., Drummond, J. R., Dufour, D., Evans, W. F. J., Fast, H., Fussen, D., Gilbert, K., Jennings, D. E., Llewellyn, E. J., Lowe, R. P., Mahieu, E., McConnell, J. C., McHugh, M., McLeod, S. D., Michaud, R., Midwinter, C., Nassar, R., Nichitiu, F., Nowlan, C., Rinsland, C. P., Rochon, Y. J., Rowlands, N., Semeniuk, K., Simon, P., Skelton, R., Sloan, J. J., Soucy, M.-A., Strong, K., Tremblay, P., Turnbull, D., Walker, K. A., Walkty, I., Wardle, D. A., Wehrle, V., Zander, R., and Zou, J.: Atmospheric Chemistry Experiment (ACE): Mission Overview, Geophys. Res. Lett., 32, L15S01, doi:10.1029/2005GL022386, 2005.
Boone, C. D., Nassar, R., Walker, K. A., Rochon, Y., McLeod, S. D., Rinsland, C. P., and Bernath, P. F.: Retrievals for the Atmospheric Chemistry Experiment Fourier Transform Spectrometer, Appl. Opt., 44, 7218-7231, 2005.

Dils, B., De Mazière, M., Müller, J. F., Blumenstock, T., Buchwitz, M., de Beek, R., Demoulin, P., Duchatelet, P., Fast, H., Frankenberg, C., Gloudemans, A., Griffith, D., Jones, N., Kerzenmacher, T., Kramer, I., Mahieu, E., Mellqvist, J., Mittermeier, R. L., Notholt, J., Rinsland, C. P., Schrijver, H., Smale, D., Strandberg, A., Straume, A. G., Stremme, W., Strong, K., Sussmann, R., Taylor, J., van den Broek, M., Velazco, V., Wagner, T., Warneke, T., Wiacek, A., and Wood, S.: Comparisons between SCIAMACHY and ground-based FTIR data for total columns of $\mathrm{CO}, \mathrm{CH}_{4}, \mathrm{CO}_{2}$ and $\mathrm{N}_{2} \mathrm{O}$, Atmos. Chem. Phys., 6, 1953-1976, 2006,

http://www.atmos-chem-phys.net/6/1953/2006/.

Donovan, D. P., Fast, H., Makino, Y., Bird, J. C., Carswell, A. I., Davies, J., Duck, T. J., Kaminski, J. W., McElroy, C. T., Mittermeier, R. L., Pal, S. R., Savastiouk, V., Velkov, D., and Whiteway, J. A.: Ozone, Column ClO, and PSC Measurements made at the NDSC Eureka Observatory $\left(80^{\circ} \mathrm{N}, 86^{\circ} \mathrm{W}\right)$ during the Spring of 1997, Geophys. Res. Lett., 24, 2709-2712, 1997.

Dupuy, E., Walker, K. A., Kar, J., Boone, C. D., McElroy, C. T., Bernath, P. F., Drummond, J. R., Skelton, R., McLeod, S. D., Hughes, R. C., Nowlan, C. R., Dufour, D. G., Zou, J., Nichitiu, F., Strong, K., Baron, P., Bevilacqua, R. M., Blumenstock, T., Bodeker, G. E., Borsdorff, T., Bourassa, A. E., Bovensmann, H., Boyd, I. S., Bracher, A., Brogniez, C., Burrows, J. P., Catoire, V., Ceccherini, S., Chabrillat, S., Christensen, T., Coffey, M. T., Cortesi, U., Davies, J., De Clercq, C., Degenstein, D. A., De Mazière, M., Demoulin, P., Dodion, J., Firanski, B., Fischer, H., Forbes, G., Froidevaux, L., Fussen, D., Gerard, P., Godin-Beekmann, S., Goutail, F., Granville, J., Griffith, D., Haley, C. S., Hannigan, J. W., Höpfner, M., Jin, J. J., Jones, A., Jones, N. B., Jucks, K., Kagawa, A., Kasai, Y., Kerzenmacher, T. E., Kleinböhl, A., Klekociuk, A. R., Kramer, I., Küllmann, H., Kuttippurath, J., Kyrölä, E., Lambert, J.-C., Livesey, N. J., Llewellyn, E. J., Lloyd, N. D., Mahieu, E., Manney, G. L., Marshall, B. T., McConnell, J. C., McCormick, M. P., McDermid, I. S., McHugh, M., McLinden, C. A., Mellqvist, J., Mizutani, K., Murayama, Y., Murtagh, D. P., Oelhaf, H., Parrish, A., Petelina, S. V., Piccolo, C., Pommereau, J.-P., Randall, C. E., Robert, C., Roth, C., Schneider, M., Senten, C., Steck, T., Strandberg, A., Strawbridge, K. B., Sussmann, R., Swart, D. P. J., Tarasick, D. W., Taylor, J. R., Tétard, C., Thomason, L. W., Thompson, A. M., Tully, M. B., Urban, J., Vanhellemont, F., Vigouroux, C., von Clarmann, T., von der Gathen, P., von Savigny, C., Waters, J. W., Witte, J. C., Wolff, M., and Zawodny, J. M.: Validation of ozone measurements from the Atmospheric Chemistry Experiment (ACE), Atmos. Chem. Phys., 9, 287-343, 2009, http://www.atmos-chem-phys.net/9/287/2009/.

Farahani E. E., Fast, H., Mittermeier, R. L., Makino, Y., Strong, K., McLandress, C., Shepherd, T. G., Chipperfield, M. P., Hannigan, J. W., Coffey, M. T., Mikuteit, S., Hase, F., Blumenstock, T., and Raffalski, U.: Nitric acid measurements at Eureka obtained in winter 2001-2002 using solar and lunar Fourier transform absorption spectroscopy: Comparisons with Observations at Thule and Kiruna and with results from three-dimensional models. J. Geophys. Res., 112, D01305, doi:10.1029/2006JD00709605, 2007. 
Fast, H., Mittermeier, R. L., and Makino, Y.: A ten-year record of Arctic trace gas total column measurements at Eureka, from 1997 to 2006, using the Bomem DA8 Fourier transform spectrometer, in preparation, 2010.

Fraser, A., Goutail, F., Strong, K., Bernath, P. F., Boone, C., Daffer, W. H., Drummond, J. R., Dufour, D. G., Kerzenmacher, T. E., Manney, G. L., McElroy, C. T., Midwinter, C., McLinden, C. A., Nichitiu, F., Nowlan, C. R., Walker, J., Walker, K. A., Wu, H., and Zou, J.: Intercomparison of UV-visible measurements of ozone and $\mathrm{NO}_{2}$ during the Canadian Arctic ACE validation campaigns: 2004-2006, Atmos. Chem. Phys., 8, 1763-1788, 2008, http://www.atmos-chem-phys.net/8/1763/2008/.

Fu, D., Walker, K. A., Mittermeier, R. L., Strong, K., Sung, K., Fast, H., Bernath, P. F., Boone, C. D., Daffer, W. H., Fogal, P., Kolonjari, F., Loewen, P., Manney, G. L., and Mikhailov, O.: Simultaneous atmospheric measurements using two Fourier transform infrared spectrometers at the Polar Environment Atmospheric Research Laboratory during spring 2006, and comparisons with the Atmospheric Chemistry Experiment-Fourier Transform Spectrometer, Atmos. Chem. Phys. Discuss., 8, 5305-5358, 2008, http://www.atmos-chem-phys-discuss.net/8/5305/2008/.

Goldman, A., Paton-Walsh, C., Bell, W., Toon, G. C., Blavier, J.F., Sen, B., Coffey, M. T., Hannigan, J. W., and Mankin, W. G.: Network for the Detection of Stratospheric Change Fourier transform infrared intercomparison at Table Mountain Facility, November 1996, J. Geophys. Res., 104, 30481-30503, 1999.

Griffith, D. W. T., Jones, N. B., McNamara, B., Walsh, C. P., Bell, W., and Bernardo, C.: Intercomparison of NDSC Ground-Based Solar FTIR Measurements of Atmospheric Gases at Lauder, New Zealand, J. Atmos. Oceanic Technol., 20, 1138-1153, 2003.

Kerzenmacher, T. E., Walker, K. A., Strong, K., Berman, R., Bernath, P. F., Boone, C. D., Drummond, J. R., Fast, H., Fraser, A., MacQuarrie, K., Midwinter, C., Sung, K., McElroy, C. T., Mittermeier, R. L., Walker, J., and Wu, H. J.: Measurements of $\mathrm{O}_{3}, \mathrm{NO}_{2}$ and temperature during the 2004 Canadian Arctic ACE Validation Campaign, Geophys. Res. Lett., 32, L16S07, doi:10.1029/2005GL023032, 2005.

Kerzenmacher, T., Wolff, M. A., Strong, K., Dupuy, E., Walker, K. A., Amekudzi, L. K., Batchelor, R. L., Bernath, P. F., Berthet, G., Blumenstock, T., Boone, C. D., Bramstedt, K., Brogniez, C., Brohede, S., Burrows, J. P., Catoire, V., Dodion, J., Drummond, J. R., Dufour, D. G., Funke, B., Fussen, D., Goutail, F., Griffith, D. W. T., Haley, C. S., Hendrick, F., Höpfner, M., Huret, N., Jones, N., Kar, J., Kramer, I., Llewellyn, E. J., López-Puertas, M., Manney, G., McElroy, C. T., McLinden, C. A., Melo, S., Mikuteit, S., Murtagh, D., Nichitiu, F., Notholt, J., Nowlan, C., Piccolo, C., Pommereau, J.-P., Randall, C., Raspollini, P., Ridolfi, M., Richter, A., Schneider, M., Schrems, O., Silicani, M., Stiller, G. P., Taylor, J., Tétard, C., Toohey, M., Vanhellemont, F., Warneke, T., Zawodny, J. M., and Zou, J.: Validation of $\mathrm{NO}_{2}$ and NO from the Atmospheric Chemistry Experiment (ACE), Atmos. Chem. Phys., 8, 5801-5841, 2008,

http://www.atmos-chem-phys.net/8/5801/2008/.

Mahieu, E., Duchatelet, P., Demoulin, P., Walker, K. A., Dupuy, E., Froidevaux, L., Randall, C., Catoire, V., Strong, K., Boone, C. D., Bernath, P. F., Blavier, J.-F., Blumenstock, T., Coffey, M., De Mazière, M., Griffith, D., Hannigan, J., Hase, F., Jones, N., Jucks, K. W., Kagawa, A., Kasai, Y., Mebarki, Y., Mikuteit, S., Nassar, R., Notholt, J., Rinsland, C. P., Robert, C., Schrems,
O., Senten, C., Smale, D., Taylor, J., Tétard, C., Toon, G. C., Warneke, T., Wood, S. W., Zander, R., and Servais, C.: Validation of ACE-FTS v2.2 measurements of $\mathrm{HCl}, \mathrm{HF}, \mathrm{CCl}_{3} \mathrm{~F}$ and $\mathrm{CCl}_{2} \mathrm{~F}_{2}$ using space-, balloon- and ground-based instrument observations, Atmos. Chem. Phys., 8, 6199-6221, 2008,

http://www.atmos-chem-phys.net/8/6199/2008/.

Manney, G. L., Daffer, W. H., Strawbridge, K. B., Walker, K. A., Boone, C. D., Bernath, P. F., Kerzenmacher, T., Schwartz, M. J., Strong, K., Sica, R. J., Krüger, K., Pumphrey, H. C., Lambert, A., Santee, M. L., Livesey, N. J., Remsberg, E. E., Mlynczak, M. G., and Russell III, J. R.: The high Arctic in extreme winters: vortex, temperature, and MLS and ACE-FTS trace gas evolution, Atmos. Chem. Phys., 8, 505-522, 2008,

http://www.atmos-chem-phys.net/8/505/2008/.

Manney, G. L., Daffer, W. H., Zawodny, J. M., Bernath, P. F., Hoppel, K. W., Walker, K. A., Knosp, B. W., Boone, C., Remsberg, E. E., Santee, M. L., Harvey, V. L., Pawson, S., Jackson, D. R., Deaver, L., McElroy, C. T., McLinden, C. A., Drummond, J. R., Pumphrey, H. C., Lambert, A., Schwartz, M. J., Froidevaux, L., McLeod, S., Takacs, L. L., Suarez, M. J., Trepte, C. R., Cuddy, D. C., Livesey, N. J., Harwood, R. S., and Waters, J. W.: Solar occultation satellite data and derived meteorological products: Sampling issues and comparisons with Aura Microwave Limb Sounder, J. Geophys. Res., 112, D24550, doi:10.1029/2007JD008709, 2007.

Meier, A., Paton-Walsh, C., Bell, W., Blumenstock, T., Hase, F., Goldman, A., Steen, A., Kift, R., Woods, P., and Kondo, Y.: Evidence of reduced measurement uncertainties from an FTIR instrument intercomparison at Kiruna, Sweden, J. Quant. Spectrosc. Radiat. Transfer, 96, 75-84, 2005.

Paton-Walsh, C., Mittermeier, R. L., Bell, W., Fast, H., Jones, N., and Meier, A.: An intercomparison of ground-based solar FTIR measurements of atmospheric gases at Eureka, Canada, J. Atmos. Oceanic Technol., 25, 2028-2036, doi: 10.1175/2008JTECHA1060.1, 2008.

Pougatchev, N. S., Connor, B. J., and Rinsland, C. P.: Infrared measurements of the ozone vertical distribution above Kitt Peak, J. Geophys. Res., 100(D8), 16689-16697, 1995.

Rodgers, C. D.: Retrieval of Atmospheric Temperature and Composition from Remote Measurements of Thermal Radiation, Rev. Geophy. Space Phys., 14, 609-624, 1976.

Rodgers, C. D.: Inverse Methods for Atmospheric Sounding: Theory and Practice, World Scientific Publishing Co. Pte. Ltd, 238 pp., 2000.

Rodgers, C. D. and Connor, B. J.: Intercomparison of remote sounding instruments, J. Geophys. Res., 108(D3), 4116, doi:10.1029/2002JD002299, 2003.

Sung, K., Strong, K., Mittermeier, R. L., Walker, K. A., Fu, D., Kerzenmacher, T., Fast, H., Bernath, P. F., Boone, C. D., Daffer, W. H., Drummond, J. R., Kolonjari, F., Loewen, P., MacQuarrie, K., and Manney, G. L.: Ground-based column measurements at Eureka, Nunavut made with two FT-IR spectrometers in spring 2004 and 2005, and comparisons with the ACE-FTS, in preparation, 2010.

Vigouroux, C., De Mazière, M., Errera, Q., Chabrillat, S., Mahieu, E., Duchatelet, P., Wood, S., Smale, D., Mikuteit, S., Blumenstock, T., Hase, F., and Jones, N.: Comparisons between groundbased FTIR and MIPAS $\mathrm{N}_{2} \mathrm{O}$ and $\mathrm{HNO}_{3}$ profiles before and after assimilation in BASCOE, Atmos. Chem. Phys., 7, 377-396, 
2007, http://www.atmos-chem-phys.net/7/377/2007/.

Wolff, M. A., Kerzenmacher, T., Strong, K., Walker, K. A., Toohey, M., Dupuy, E., Bernath, P. F., Boone, C. D., Brohede, S., Catoire, V., von Clarmann, T., Coffey, M., Daffer, W. H., De Mazière, M., Duchatelet, P., Glatthor, N., Griffith, D. W. T., Hannigan, J., Hase, F., Höpfner, M., Huret, N., Jones, N., Jucks, K., Kagawa, A., Kasai, Y., Kramer, I., Kllmann, H., Kuttippurath, J., Mahieu, E., Manney, G., McElroy, C. T., McLinden, C., Mébarki, Y., Mikuteit, S., Murtagh, D., Piccolo, C., Raspollini, P., Ridolfi, M., Ruhnke, R., Santee, M., Senten, C., Smale, D., Tétard, C., Urban, J., and Wood, S.: Validation of $\mathrm{HNO}_{3}, \mathrm{ClONO}_{2}$, and $\mathrm{N}_{2} \mathrm{O}_{5}$ from the Atmospheric Chemistry Experiment Fourier Transform Spectrometer (ACE-FTS), Atmos. Chem. Phys., 8, 3529-3562, 2008, http://www.atmos-chem-phys.net/8/3529/2008/.
Wunch, D., Taylor, J. R., Fu, D., Bernath, P., Drummond, J. R., Midwinter, C., Strong, K., and Walker, K. A.: Simultaneous groundbased observations of $\mathrm{O}_{3}, \mathrm{HCl}, \mathrm{N}_{2} \mathrm{O}$, and $\mathrm{CH}_{4}$ over Toronto, Canada by three Fourier transform spectrometers with different resolutions, Atmos. Chem. Phys., 7, 1275-1292, 2007, http://www.atmos-chem-phys.net/7/1275/2007/. 